\title{
Identificação e mapeamento em mesoescala da zona proglacial da geleira Collins, ilha Rei George, Antártica.
}

\section{Identification and mesoscale mapping of the proglacial zone of the Collins glacier, King George Island, Antarctica.}

\author{
Carina Petsch ${ }^{\text {ad }}$, Rafaela Mattos Costa ${ }^{\mathrm{e}}$, Kátia Kellem da Rosa ${ }^{\mathrm{f}}$, \\ Rosemary Vieira ${ }^{\mathrm{cg}}$, Jefferson Cardia Simões ${ }^{\text {bh }}$ \\ ${ }^{a}$ Universidade Federal de Santa Maria (UFSM), ${ }^{b} U F R G S,{ }^{c} U F F$ \\ dcarinapetsch@gmail.com, ${ }^{\mathrm{e}}$ raffaellamattos@hotmail.com, ${ }^{\mathrm{f} k a t i a k e l l e m @ g m a i l . c o m, ~}$ \\ grosemaryvieira@id.uff.br, hjefferson.simoes@ufrgs.br
}

\begin{abstract}
Resumo
O objetivo desta pesquisa é caracterizar e interpretar os processos geomorfológicos e formação de geoformas do ambiente proglacial, incluindo a área marginal ao gelo da geleira Collins, Ilha Rei George, Antártica. Foram coletadas 17 amostras nas feições geomorfológicas proglaciais distais e marginais ao gelo. Foi realizada a análise granulométrica e morfoscópica dos grãos e também a presença de estrias e textura da amostra. A partir da identificação dos tipos de feições deposicionais foi feito um mapeamento geomorfológico de mesoescala da zona proglacial. Foram encontradas feições denominadas de flutings, morainas recentes indicativas da retração da geleira e morainas antigas resultantes do avanço. As morainas de avanço indicam a posição da frente da geleira durante a Pequena Idade do Gelo (PIG) e atualmente, encontram-se na zona proglacial distal. A área mapeada na Geleira Collins foi dividida em quatro setores: 1, 2, 3 e 4. Os setores 1, 2 e 3 apresentam uma série de morainas de recessão e flutings com material arredondado e pouco anguloso indicando geleira pouca espessa, retração e ambiente com presença de água líquida. O setor 4 apresenta uma parte da geleira ativa com capacidade de transporte de material com diferentes granulometria e formação de morainas de recessão/estagnação maiores que no setor 1 e 2 .
\end{abstract}

Palavras-chave: glaciologia; zona proglacial; morainas; sedimentos; geleiras.

\begin{abstract}
The objective of this research is to characterize and interpret the geomorphological processes and formation of geoforms of the proglacial environment, including the fringing area of the Collins glacier, King George Island, Antarctica. Seventeen samples were collected in the proglacial geomorphological features distal and marginal to the ice. The granulometric and morphoscopic analyzes of the grains were performed, as well as the presence of striae and sample texture. From the identification of the types of depositional features, a mesoscale geomorphological mapping of the proglacial area was made. Features were denominated of flutings, recent moraines indicative of the retraction of the glacier and old morainas resulting from the advance. Forward moraines indicate the position of the front of the glacier during the Little Ice Age (LIA) and are currently in the distal proglacial area. The studied area in Collins Glacier was subdivided into four sections: 1, 2, 3 and 4. Sections 1, 2 and 3 present a series of recession moraines and flutings with rounded and slightly angled material indicating little thick glacier, retraction and environment with presence of liquid water. Sector 4 presents a part of the active glacier with capacity to transport material with different grain size and formation of moraines of recession / stagnation larger than in sector 1 and 2.
\end{abstract}

Key-words: glaciology, proglacial zone, moraines, sediments, glaciers.

\section{Introdução}

Conforme uma geleira sofre processo de retração da sua frente, se iniciam processos de retrabalhamento pela ação do vento, fluxos gravitacionais, fluvial, precipitação líquida e consequente intemperismo químico e físico dos depósitos recentemente expostos (Mercier, 2008; Mercier e Étienne, 2008), a formação de morainas evidencia o padrão de avanço/retração das geleiras (Benn e Evans, 2010).
A dinâmica de degelo das geleiras é importante para construir relações sobre transporte sedimentar e a formação de geoformas deposicionais relacionadas à dinâmica das geleiras (Fountain e Walder, 1998). Características sedimentológicas e geomorfológicas glaciais podem ser usadas para interpretar os processos subglaciais, inferir as condições termo-basais, a dinâmica de avanço e recuo da geleira e, assim, reconstruir a evolução do ambiente de deglaciação 
(Bennett e Glasser 1996, Glasser e Hambrey 2002, Glasser et al. 2005).

Com o recente processo de retração de geleiras na região da Península Antártica e ilhas adjacentes, torna-se importante o monitoramento das respostas da dinâmica glacial e proglacial e as interligações existentes. Além disso, a península Fildes é uma das áreas livres de gelo de maior extensão (cerca de $30 \mathrm{~km}^{2}$ ) na Antártica Marítima e, portanto, o monitoramento dos processos proglaciais que ocorrem nesses locais são importantes (Michel et al. 2014).

O objetivo desta pesquisa é caracterizar e interpretar os processos geomorfológicos e a formação de geoformas do ambiente proglacial, incluindo a área marginal ao gelo e distal da geleira Collins, ilha Rei George, Antártica.

\section{Caracterização da área}

As ilhas do arquipélago Shetland do Sul são separadas da América do Sul pelo Mar de Drake, e da Península Antártica pelo Estreito de Bransfield. As ilhas pertencem a um grupo de ilhas que, supostamente, compartilham a mesma história geológica e tectônica. As Ilhas Shetland do Sul podem conter rochas vulcânicas e plutônicas do Cretáceo Inferior e do início do Mioceno, relacionada à subducção do Pacífico abaixo do continente antártico (Smellie, 1983). O vulcanismo subsequente do Mioceno (Birkenmajer et al. 1990) está associado a rifteamento no Estreito de Bransfield. A Península Fildes é composta por uma espessa sucessão de basalto e andesito (pode até ser dacítica) com intercalações de rochas vulcanoclásticas (Hawkes, 1961).

De uma forma geral, Bremer (2008) afirma que as áreas livres de gelo das ilhas Shetland do Sul são compostas por terrenos jovens e drenados por canais intermitentes e a morfodinâmica está associada a processos físicos e químicos devido ao derretimento da neve e do gelo. Os processos geomorfológicos que ocorrem atualmente na Península Fildes são nivação, solifluxão, ablação e erosão e crioturbação (Simas et al. 2008). De acordo com Michel et al. (2014), os solos da Península Fildes são bem desenvolvidos para padrões antárticos, sendo os criossolos dominantes relacionados a crioturbação e processos da camada ativa.

A geleira Collins (Figura 1) encontra-se no setor norte da Península Fildes e caracteriza-se como um pequeno domo de gelo aproximadamente na latitude $62^{\circ} 12^{\prime} \mathrm{S}$ e longitude $58^{\circ} 57^{\prime} \mathrm{W}$, com uma área de $15 \mathrm{~km}^{2}$ e elevação máxima de $270 \mathrm{~m}$ e término atual em terra (Simões et al. 2015). 

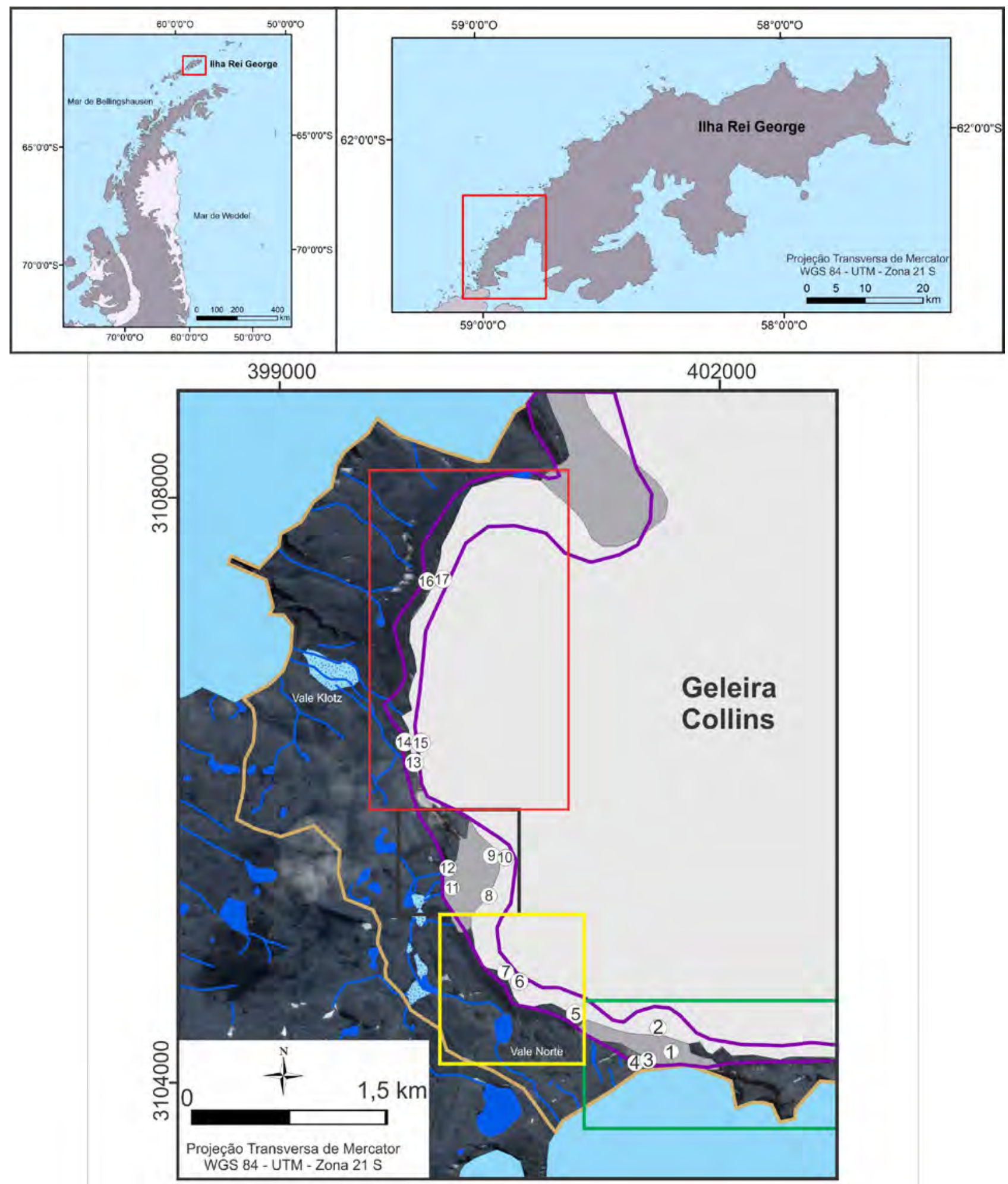

\section{Legenda}

Setores de mapeamento

$\square$ Setor 1
$\square$ Setor 2
$\square$ Setor 3
$\square$ Setor 4

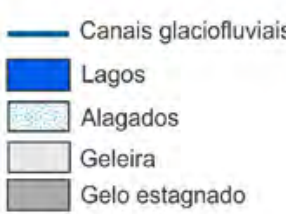

(1) Amostras

Ambientes

Proglacial marginal

Proglacial distal

Figura 1: A - Península Antártica com quadrado vermelho indicando a Ilha Rei George; B - Ilha Rei George com quadro em vermelho destacando a Península Fildes; C - Área proglacial da geleira Collins indicando a localização das amostras coletadas e setores mapeados. 


\section{Materiais e métodos}

Foram coletadas 17 amostras (Figura 1) distribuídas ao longo de feições geomorfológicas (morainas e flutings) nas áreas proglaciais distais e marginais ao gelo para obter o mapeamento de detalhe da área. As áreas de coleta foram escolhidas para serem representativas de cada feição. As atividades de campo foram realizadas durante os verões de 2014/2015 e $2015 / 2016$.

As amostras foram coletadas com uma pá, na parte subsuperficial da feição, na quantidade aproximada de $100 \mathrm{~g}$ e colocadas em sacos plásticos com o código de cada amostra. Em cada local de coleta foram realizados pontos de controle de GPS (altitude geométrica e coordenadas) e observação do ambiente de entorno (orientação, tamanho do depósito, matriz).

\subsection{Análise granulométrica}

A separação dos sedimentos, finos e grosseiros foi realizado por um conjunto de peneiras com malha decrescente até o limite de $0,062 \mathrm{~mm}$, visando a separação de acordo com classes texturais. Em seguida realizou-se a pesagem por classe (Figura 2).

Esses dados foram processados usando o software GRADISTAT, obtendo-se assim, a distribuição percentual das classes texturais dos sedimentos segundo a escala de Wentworth (1922). Foram elaborados histogramas para analisar a distribuição granulométrica e se o mesmo é unimodal, bimodal ou multimodal.

\subsection{Análise morfoscópica}

A análise foi realizada em 50 grãos das três classes granulométricas de maior intervalo. O grau de arredondamento foi calculado usando a tabela de comparação de Krumbein (1941) e o grau de esfericidade medido pela tabela de Rittenhouse (1943). As análises das texturas superficiais foram realizadas pela classificação de Bigarella (1955). Para a análise da presença de estrias nas amostras utilizou-se uma lupa binocular.

A forma do clasto foi definida pela dimensão relativa dos três eixos ortogonais, chamados a (maior), b (intermediário), e c (menor) (Hubbard e Glasser, 2005). Os dados da forma dos clastos foram plotados em diagramas triangulares, colocando os raios dos três eixos ortogonais da partícula e realizados com o programa TriPlot. O índice RA (\% dos clastos angulosos) e índice $\mathrm{C}_{40}(\%$ de clastos cujo eixo c/a é $<0,4)$ também foram calculados (Figura 2).

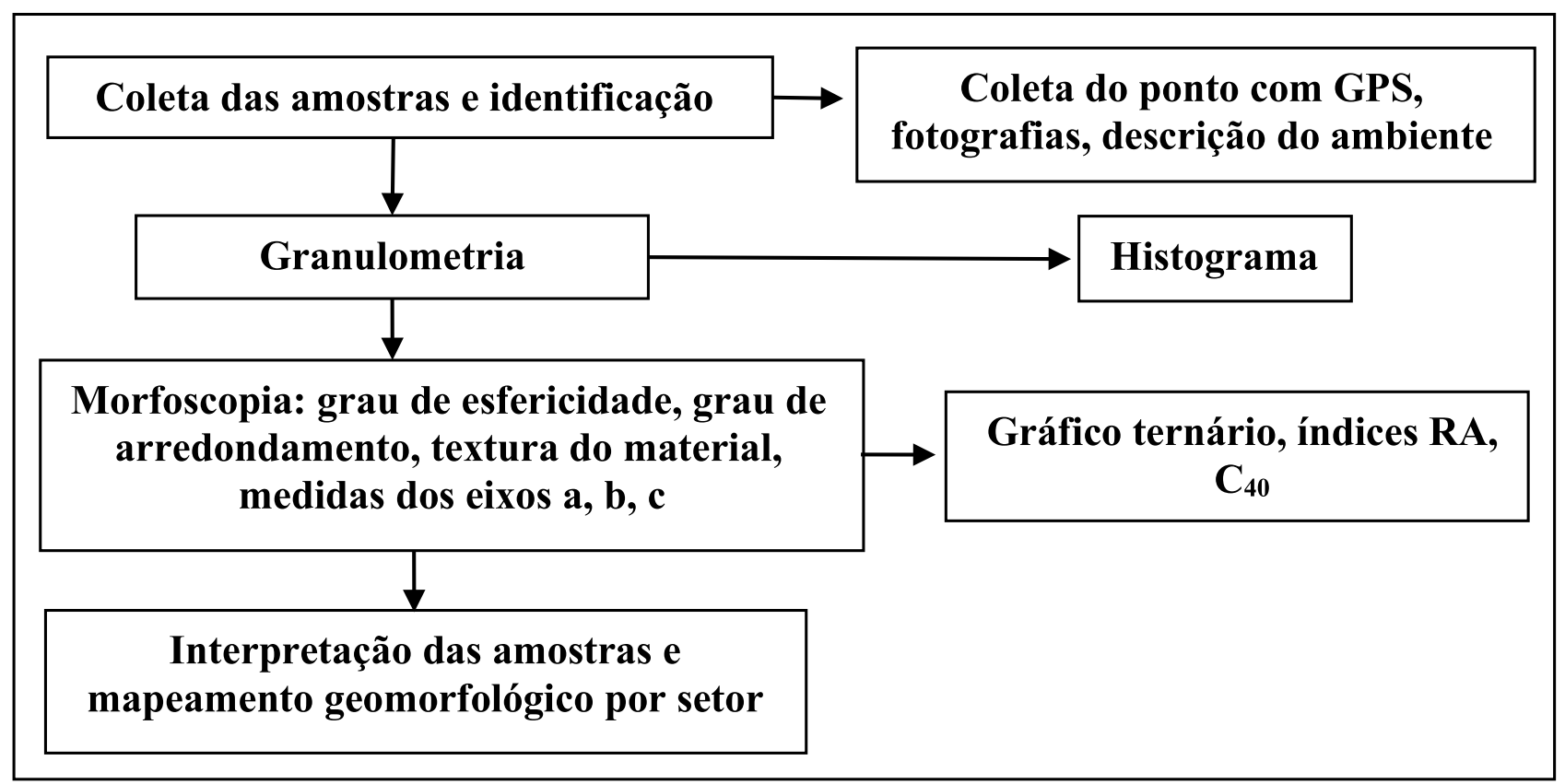

Figura 2: Metodologia adotada para a interpretação dos depósitos geomorfológicos analisados neste trabalho. 


\subsection{Mapeamento geomorfológico de mesoescala da zona proglacial}

O mapeamento geomorfológico dos ambientes e geoformas deposicionais, proglacial distal e marginal ao gelo, foi realizada para feições de mesoescala. As feições foram identificadas pela análise de registros sedimentares, interpretação geomorfológica em campo e na imagem QuickBird (de fevereiro de 2008).

Foi criada uma chave de interpretação (Tabela 1) para definição e a identificação das formas para o mapeamento geomorfológico baseada em Glasser et al. (2005), Hubbard e Glasser (2005), Smith e Clark (2005), Gustavsson et al.(2006).

O degradê de cores varia entre tons escuros (vermelho) para as feições morâinicas mais antigas a tons claros (amarelo) para as feições mais recentes. Essa dedução se baseia na interpretação sedimentológica, contudo não foi realizada datação. Não foi possível delimitar morainas recentes de recessão que se apresentam isoladas, devido à escala, sendo então gerado um polígono para a região em que estas se concentram.

Tabela 1: Chave de interpretação das feições deposicionais proglaciais distais e de contato com a geleira. Os setores foram identificados na Figura 1.

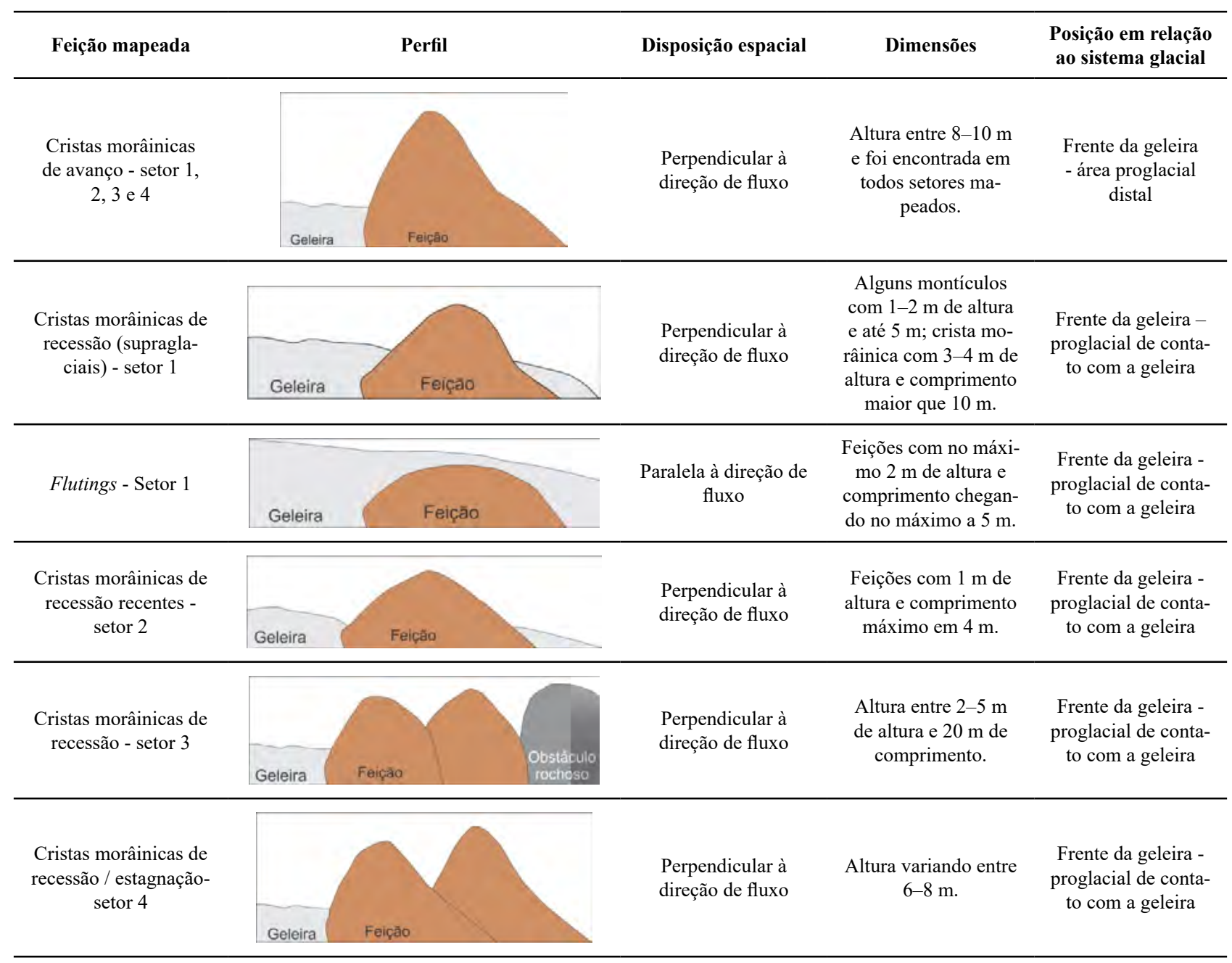




\section{RESULTADOS E DISCUSSÕES}

\subsection{Análise sedimentológica e interpretação de geoformas deposicionais}

Os resultados da análise granulométrica e morfoscópica foram a base para a interpretação da história de transporte, erosão e deposição das feições glaciais e, assim, para a identificação desses e de ambientes sedimentares associados. Foram encontradas feições denominadas de flutings, morainas recentes indicativas da retração da geleira e morainas antigas resultantes de avanço.

\subsubsection{Setor 1 - Flutings}

Os depósitos identificados em campo possuem em média $2 \mathrm{~m}$ de altura e $4-5 \mathrm{~m}$ de extensão, com uma seção transversal uniforme que geralmente se inicia por um obstáculo rochoso. São feições compostas por till de alojamento e também contêm areias e cascalhos (Bennett e Glasser 1996, Eklund e Hart 1996).

Nos depósitos interpretados como flutings (Figura 3 - Amostra 3 e 4) observa-se predominância textural de cascalho e areia $(42 \%$ e $57 \%$ para amostra 3, respectivamente; $53 \%$ e $44 \%$ para a amostra 4 ). Somente grãos acima de $4 \mathrm{~mm}$ apresentam esfericidade média, subarredondamento e estrias, abaixo de 4 $\mathrm{mm}$ predominam grãos com esfericidade média e o arredondamento sub-angular, textura sacaróide fosco, índice RA em 30\%, esfericidade média e índice $\mathrm{C}_{40}$ de $32 \%$ e $20 \%$, para as amostras 3 e 4 , respectivamente (Figura 3). A presença de estrias e o grau de arredondamento encontrado indica transporte subglacial, e/ou glaciofluvial, contudo, outras características apresentadas indicam que a amostra possui mistura de sedimentos de diferentes períodos de transporte.
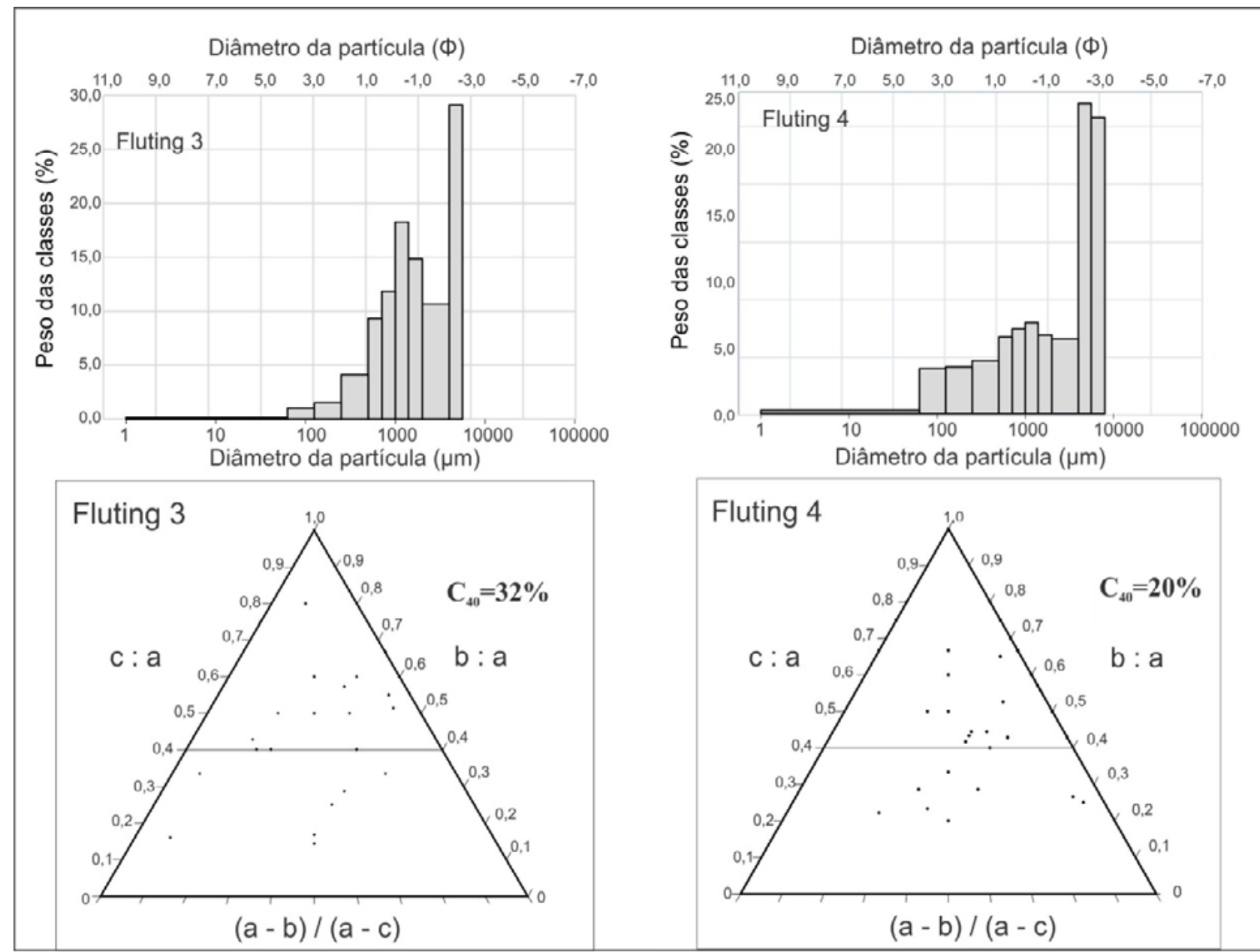

Figura 3: Análise granulométrica e morfoscópica das amostras 3 e 4 caracterizadas como flutings. Os valores baixos de $\mathrm{C}_{40}$ indicam material retrabalhado. 


\subsubsection{Setor 1 - Morainas de recessão (formadas por material supraglacial)}

A amostra 1 (Figura 4) é composta por sedimentos de fração cascalho de médio a fino $(94,3 \%)$ a areia $(5,5 \%)$, com quase ausência de sedimentos finos, muito bem selecionada e com distribuição unimodal. Grãos de baixo arredondamento $(65 \%)$ e esfericidade média (48\%) predominam. O índice RA é de $45 \%$ e possui alto índice $\mathrm{C}_{40}(90 \%)$.

$\mathrm{Na}$ amostra 2 predominam sedimentos de fração predominante de cascalho de médio a fino $(85 \%)$, areia $(15 \%)$, evidencia-se quase ausência de sedimentos finos, apresenta-se bem selecionada e com distribuição unimodal. Os sedimentos têm baixo arredondamento, com predomínio de $48 \%$ da classe angular e $36 \%$ subangular, e esfericidade média (54\%) a baixa (40\%). O índice RA é $48 \%$ e possui alto $\mathrm{C}_{40}(76 \%)$.

Os relativos altos índices de $\mathrm{C}_{40}$ e predomínio de grãos com raios c/a pequenos indicam grãos mais alongados e imaturos e a alta angularidade e pouca esfericidade podem resultar da grande quebra que sofrem os grãos. As características de pouco selecionamento, esfericidade e arredondamento indicam transporte passivo e da pouca distância de transporte.

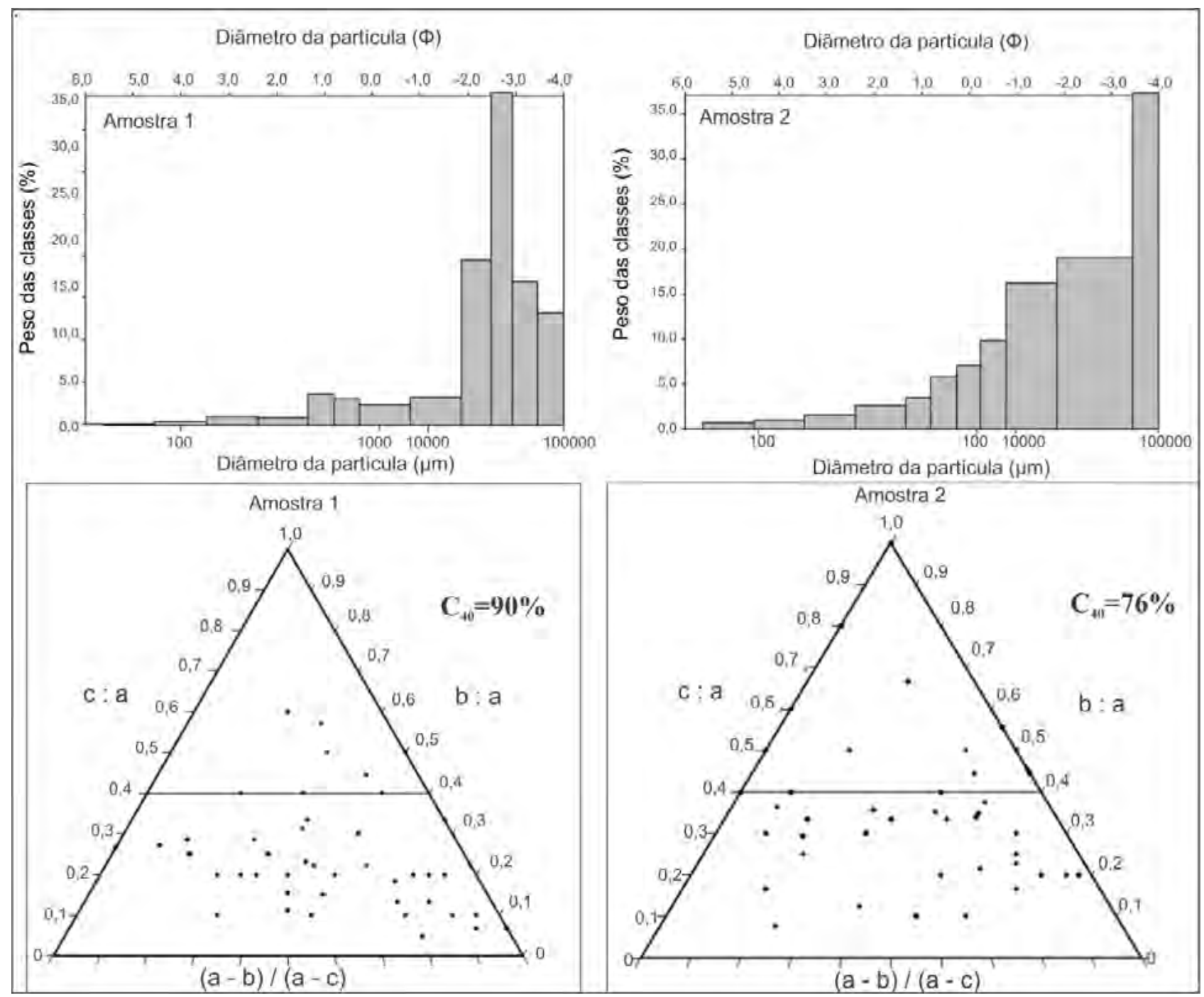

Figura 4: Análise granulométrica e morfoscópica das amostras 1 e 2. As feições se caracterizam pela quase ausência de sedimentos finos e grãos de pouca esfericidade. 


\subsubsection{Setor 2 - Morainas de recessão recentes}

É possível observar uma sequência de pequenos depósitos de cristas irregulares (com altura média entre 1-2 $\mathrm{m}$ e extensão de até $5 \mathrm{~m}$ ) e que as características sedimentares mostram ser morainas, no setor nordeste da península Fildes. A análise granulométrica das amostra 5 e 6 (Figura 5) indica que predominam areia e cascalho, pobremente selecionada e distribuição bimodal. Os grãos são predominantemente sub arredondados e de esfericidade média, com índice RA em $30 \%$ e $20 \%$ (amostra 5 e 6 ). Há poucas estrias e a textura predominante é sacaróide fosco. $\mathrm{O}$ baixo índice
$\mathrm{C}_{40}(12 \%$ e $40 \%$ para as amostras 5 e 6 , respectivamente) indica transporte ativo.

As características dessas morainas apontam formação na margem de geleira com base úmida, pela presença de água de derretimento e retração da geleira, já como observado em estudos anteriores na área (Simões et al. 2015) e criadas por uma combinação de processos de despejo e empurrão. O predomínio de grãos grosseiros, a pouca quantidade de finos e o selecionamento indica que os sedimentos da amostra foram modificados por processos erosivos em ambiente englacial e supraglacial ou ocorreu transporte curto (alguns metros) para a modificação dos grãos.

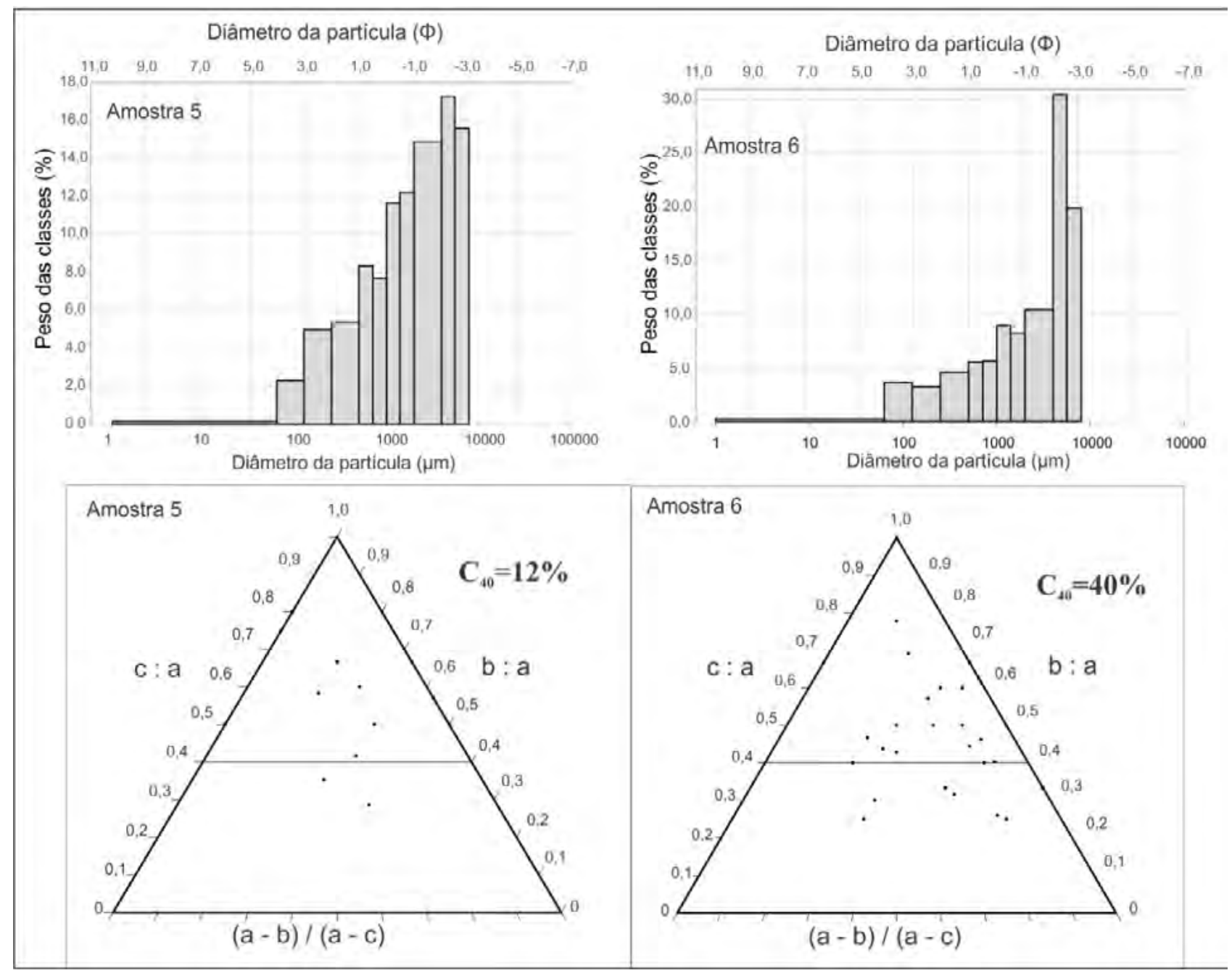

Figura 5: Análise morfoscópica e granulométrica das amostras 5 e 6. O baixo índice $\mathrm{C}_{40}(12 \%$ e $40 \%$ para as amostras 5 e 6 , respectivamente) indica transporte ativo. 


\subsubsection{Setor 3: Morainas de recessão (formadas em ambiente glaciofluvial)}

As feições morâinicas representadas pelas amostras 11 e 12 (Figura 6), possuem extensão entre $1-5 \mathrm{~m} \mathrm{e}$ altura máxima de $2 \mathrm{~m}$, se localizam isoladamente ao lado de um canal de água de derretimento, na margem frontal da geleira.

A amostra 11, localizada à jusante de um obstáculo rochoso, caracteriza-se por ser unimodal, com $73 \%$ de cascalho e $27 \%$ de areia. Predomina arrendondamento sub angular com índice RA em 25\%, esfericidade baixa, textura superficial sacaróide fosca. $O$ índice
$\mathrm{C}_{40}$ é de $30 \%$ indica o papel do transporte por água de derretimento neste local, o que é evidenciado por vários canais em um sistema de leque glaciofluvial na área, além do arrancamento de material proveniente da área rochosa exposta à jusante.

A amostra 12 indica predominância de areia (54\%) e cascalho (44\%) e é pobremente selecionado. Apresenta estrias, predominância de esfericidade média, arredondamento médio e textura de sacaróide fosco. A amostra possui índice RA de $5 \%$ e $_{40}$ de $22 \%$. Essas características evidenciam atividade erosiva subglacial com a presença de água de degelo.

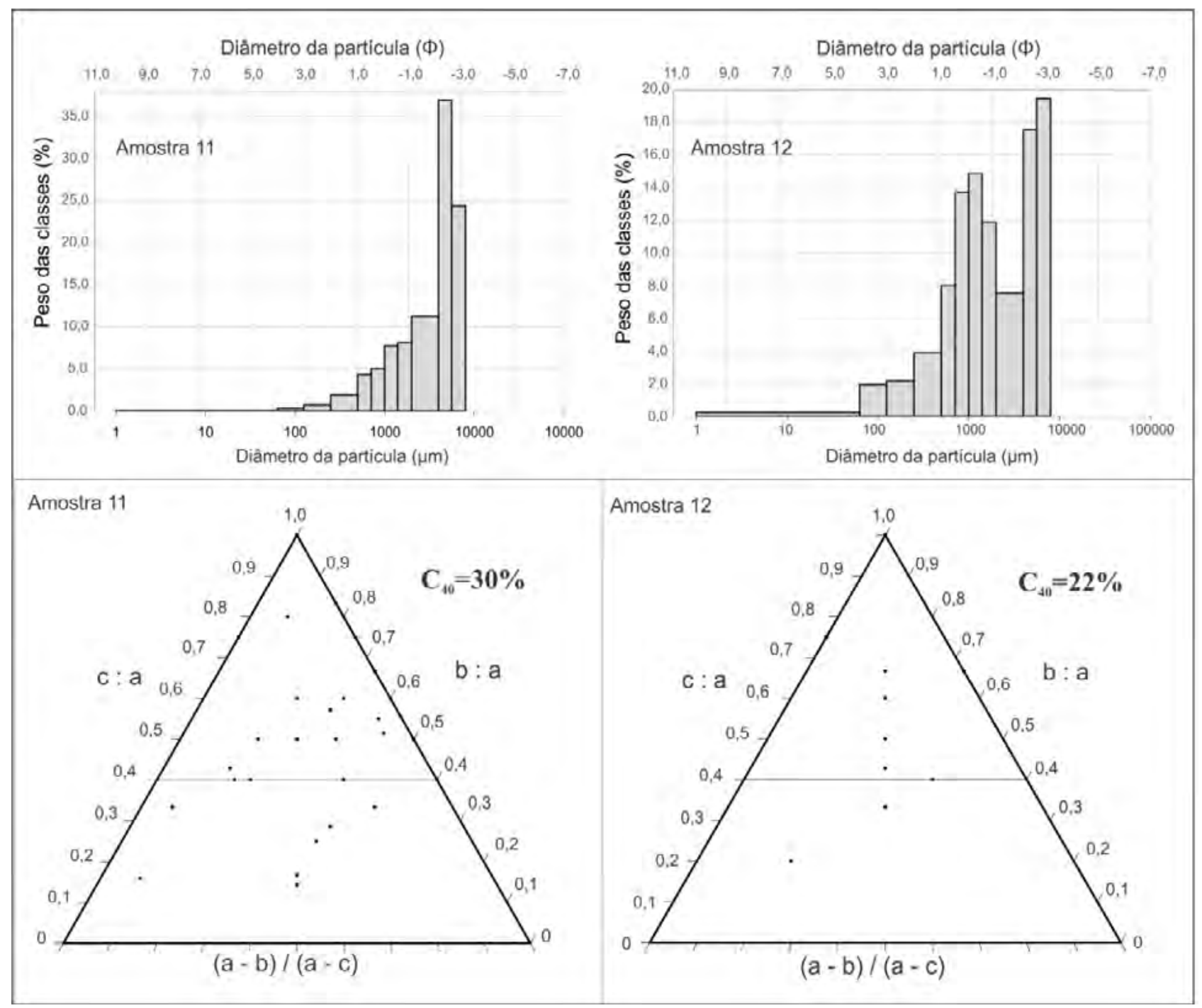

Figura 5: Análise morfoscópica e granulométrica das amostras 5 e 6. O baixo índice $\mathrm{C}_{40}(12 \%$ e $40 \%$ para as amostras 5 e 6 , respectivamente) indica transporte ativo. 


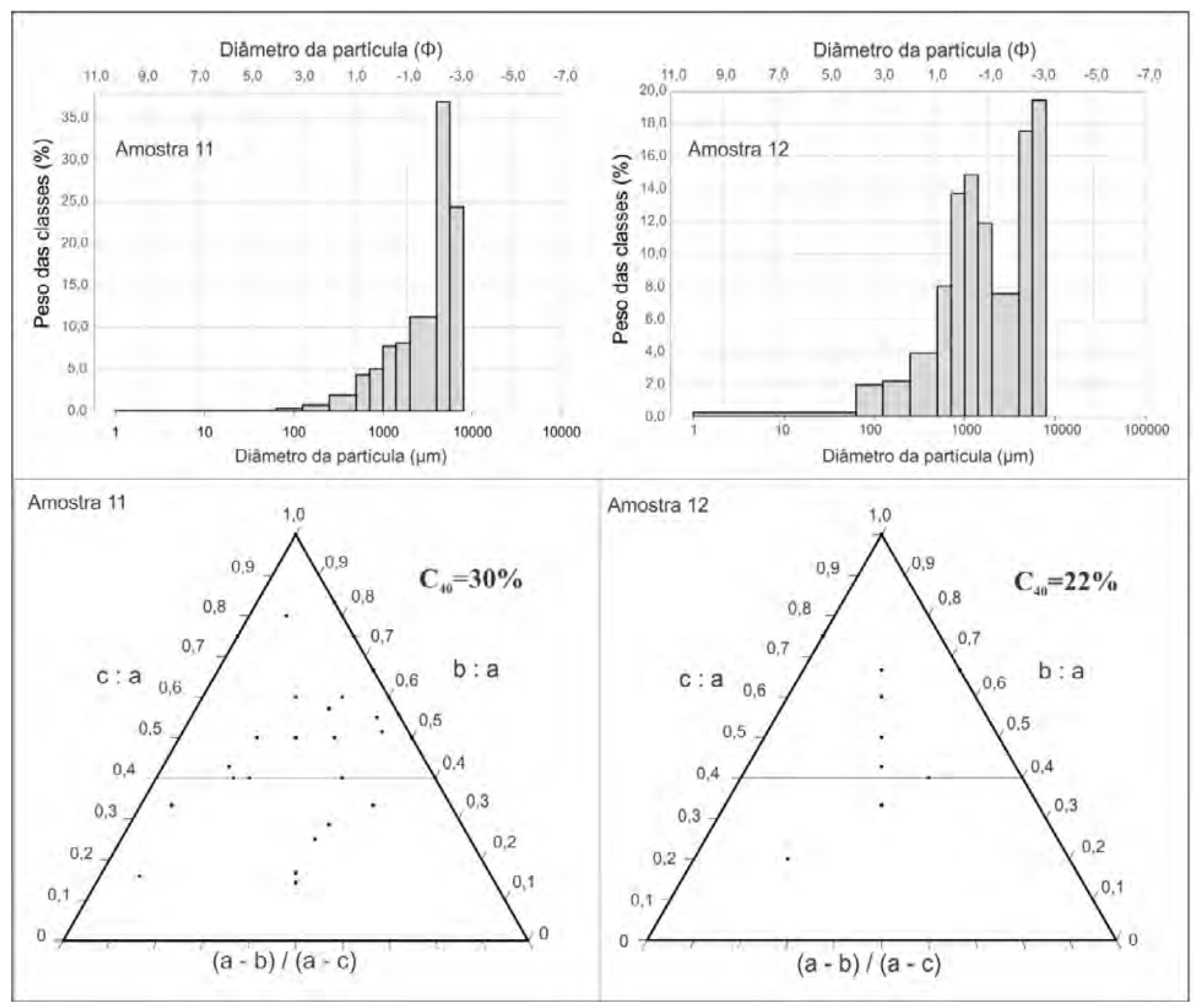

Figura 6: Análise morfoscópica e granulométrica das amostras 11 e 12. As diferentes características das amostras se devem a uma área rochosa exposta à jusante, que transfere quantidades de sedimentos diferentes para essas feições. 


\subsubsection{Setor 3 - Morainas de recessão (formadas por obstáculo rochoso)}

As amostras 8 e 9 (Figura 7), interpretadas como morainas, possuem sua formação provavelmente relacionada à mesma época de retração da geleira (pós Pequena Idade do Gelo), pois apresentam índices $\mathrm{C}_{40}$ e RA semelhantes. Formam uma crista morâinica que, possivelmente, no passado possuía ligação longitudinal. Possuem $7 \mathrm{~m}$ de altura e extensão máxima de $30 \mathrm{~m}$.

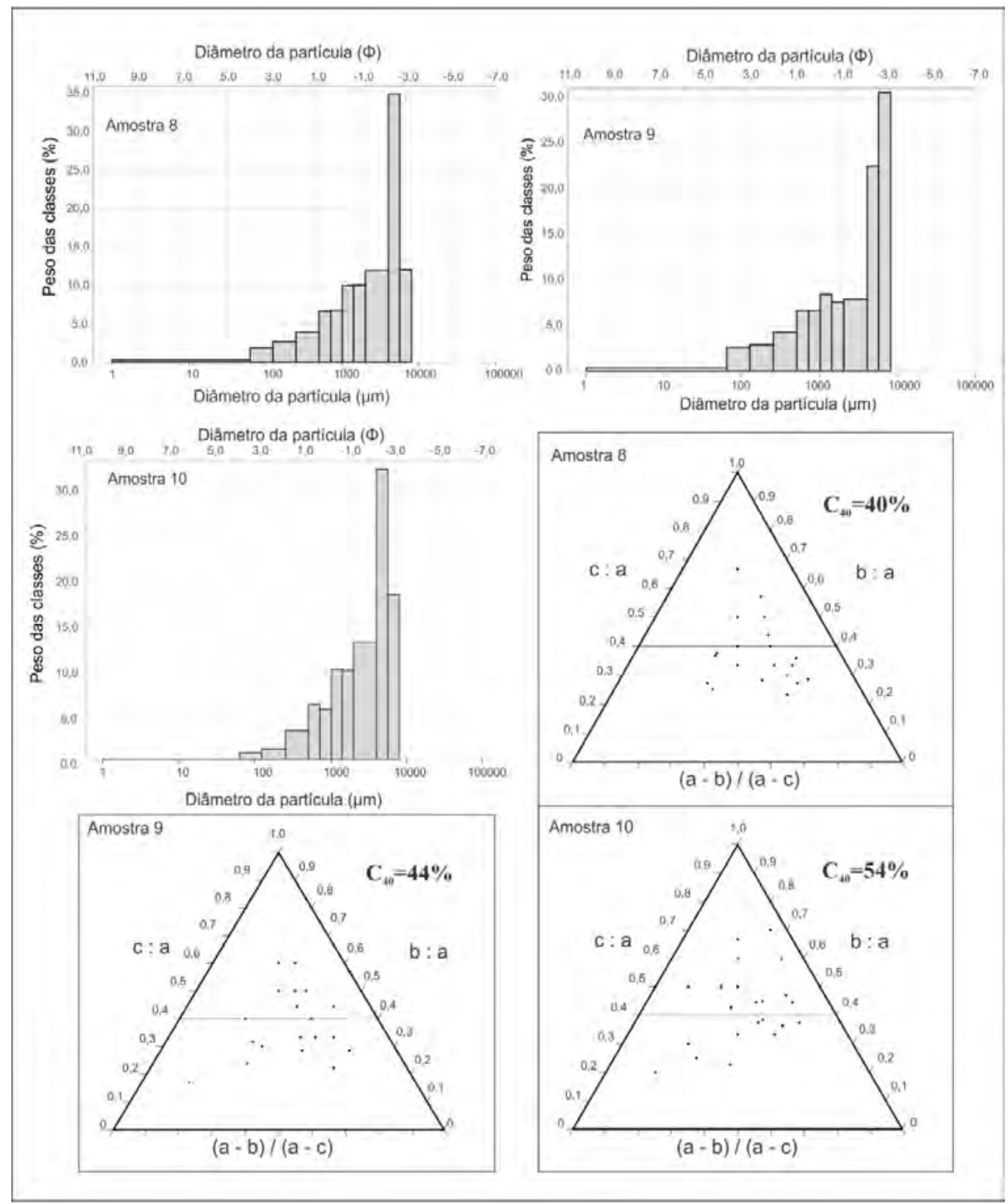

Figura 7: Análise morfoscópica e granulométrica das amostras 8,9 e 10. As amostras 8 e 9 possuem sua formação provavelmente relacionada à mesma época de retração da geleira (pós Pequena Idade do Gelo).

As amostras 8 e 9 apresentam $57 \%$ de cascalho, $41 \%$ de areia, pobremente selecionada com areia grossa e cascalho fino. Há poucas estrias ou grãos sacaróides polidos. Apresenta esfericidade baixa, o arredondamento predomina em angular/sub-angular, e o índice RA é de $50 \%$ e $67 \%$ e o índice $\mathrm{C}_{40}$ é de $40 \%$ e $44 \%$ (ambos os valores, respectivamente para amostras 8 e 9 ).

Atualmente, as morainas representadas pelas amostras 8 e 9 (Figura 7) indicam um limite de frente da geleira, já que possivelmente o gelo localizado à sua jusante está estagnado e em anos de maior ablação como 2008 perde conexão com o sistema glacial principal.

Já a moraina 10 (Figura 7), formada em posição distal em relação a moraina 9 , é uma feição de recessão influenciada pela presença de um obstáculo rochoso, que diminui a velocidade da geleira, tornando-a menos espessa e com menor competência de transporte sedimentar. Apresenta $65 \%$ de cascalho e $34 \%$ de areia, pobremente selecionada, esfericidade predominante baixa, arredondamento angular, índice RA de 56\%, sem estrias e índice $\mathrm{C}_{40}$ de $54 \%$. 


\subsection{6 - Setor 4 - Morainas de recessão/estagnação}

As três cristas morâinicas (amostras 15, 16 e 17), encontradas no setor de mapeamento 4, podem estar relacionadas a uma sequência de retração e estabilização do setor frontal da geleira Collins no quadrante noroeste. A amostra 16 (Figura 8) está entre a moraina de avanço (amostra 15) e a moraina mais recente (amostra 17) do setor 4 e representa, possivelmente, uma fase de retração depois do avanço da pequena Idade do Gelo, trata-se de uma moraina com 4-6 m de altura. A amostra 17 possui contato direto com a geleira, entre 3-6 m de altura, e a amostra 15 possui características muito similares às encontradas no setor 2 , contudo apresentam maior continuidade longitudinal e maior altura (6-8m), sendo possivel encontrar grãos como blocos de $40 \mathrm{~cm} \times 30 \mathrm{~cm}$.

A análise granulométrica da amostra 15 indica que há predominância de cascalho (76\%) e areia $(21,8 \%)$, caracterizando-se por ser pobremente selecionada e com distribuição bimodal. Predominam grãos sub- angulares a sub arredondados, com a presença de grãos arredondados. A esfericidade predominante é de média, índice $\mathrm{C}_{40}$ é de $40 \%$ e o RA é de $1 \%$. Apresenta sedimentos de textura superficial com muitos sulcos, estrias e predomínio de grãos mamelonados foscos.

A moraina 16 apresenta $40 \%$ de classe textural cascalho e $57 \%$ areia. Predomina o arredondamento angular, esfericidade baixa (75\%), índice RA $63 \%$ e índice $\mathrm{C}_{40}$ de $50 \%$, sem a presença de estrias e predomínio de grãos com textura sacaróide fosca.

A moraina 17 (Figura 8) possui predominância textural de cascalho (62\%) e areia (37\%), caracterizando-se como pobremente selecionada, esfericidade predominante baixa (40\%), angulosidade predomina em sub-arredondados, textura sacaróide fosco, poucas estrias, RA de $35 \%$ e índice $\mathrm{C}_{40}$ de $32 \%$. A esfericidade e arredondamento indicam maior distância de transporte dos sedimentos e modificação subglacial com a presença de água de degelo, ainda que possa ter mistura de grãos de diferentes origens de transporte. 


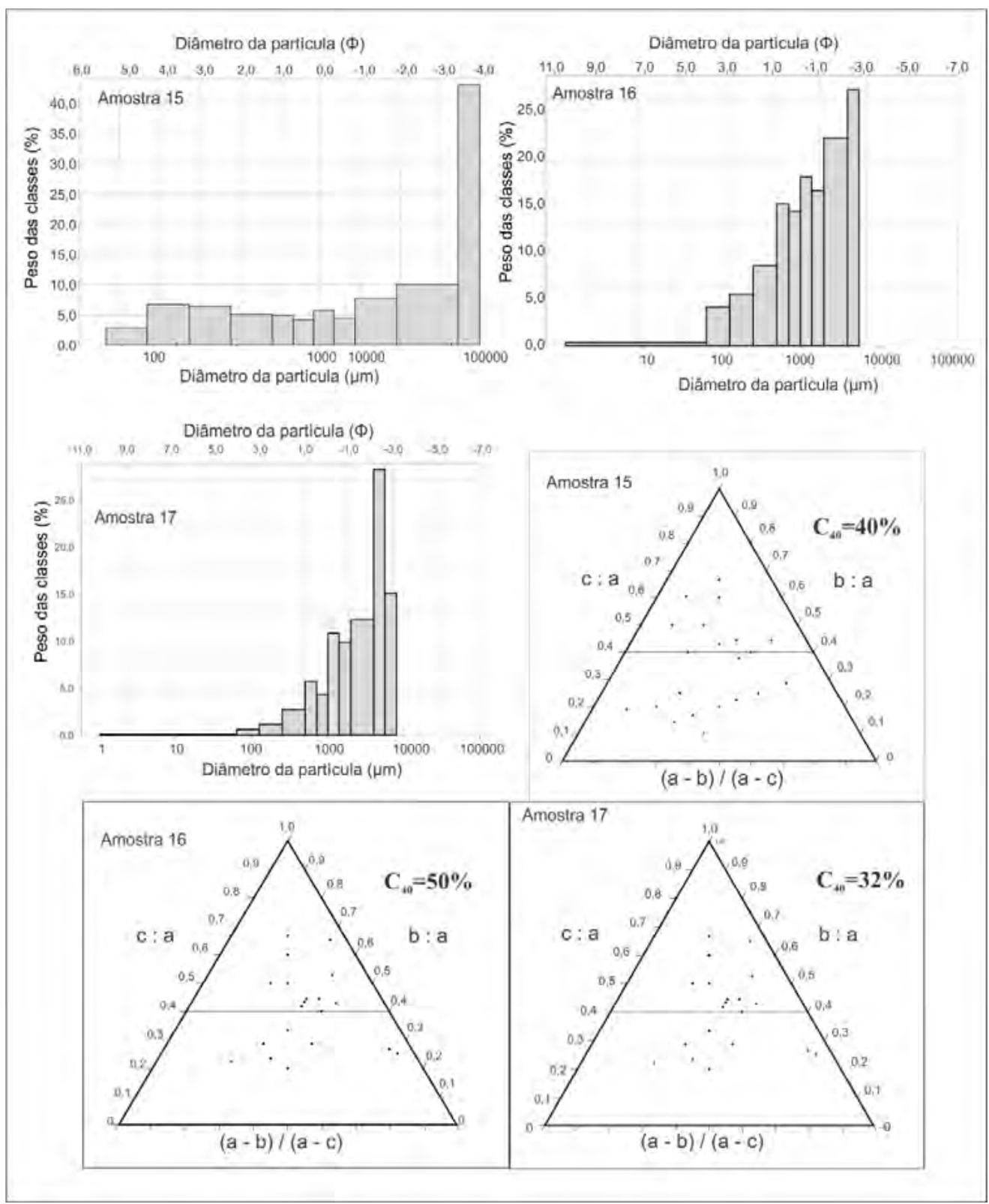

Figura 8: Análise morfoscópica e granulométrica das amostras 15, 16 e 17. Predominam grãos sub-angulares a sub arredondados, com a presença de sedimentos arredondados. A mistura de grãos indica diferentes origens de transporte. 


\subsubsection{Setor 1, 2 e 4 - Morainas de avanço}

As amostras 7, 13 e 14 apresentam-se distribuídas nos setores 1,2 e 4 com altura chegando a $10 \mathrm{~m}$ e extensão de $800 \mathrm{~m}$. Se distinguem pela continuidade e altura em relação as demais feições de deposição encontradas. Por sua localização, podem ser interpretadas como morainas de avanço relacionadas à datação por radiocarbono de Hall (2007), que evidencia a extensão do campo de gelo da ilha Rei George sobre a península Fildes no Holoceno tardio. A crista morâinica comumente mostra-se $10 \mathrm{~m}$ acima do nível gelo atual e parte dela pode ter sido formada por processo de empurrão durante a fase de avanço.
A amostras 7, 13 e 14 (Figura 9) são compostas predominantemente por cascalho $(55-72 \%)$ e areia (27-44\%), destacando-se por possuir maior quantidade de fração cascalho que as morainas relacionadas a fases mais recentes, ou seja material mais imaturo e pouco tempo de transporte. No geral, o arredondamento predominante é angular, esfericidade baixa a média, índice RA entre 38 e $64 \%$, índice $\mathrm{C}_{40}$ entre $44 \%$ e $50 \%$ e textura superficial sacaróide fosco, com poucas estrias. As características sedimentares indicam relativo transporte subglacial e posterior deposição durante o período de estagnação do avanço.

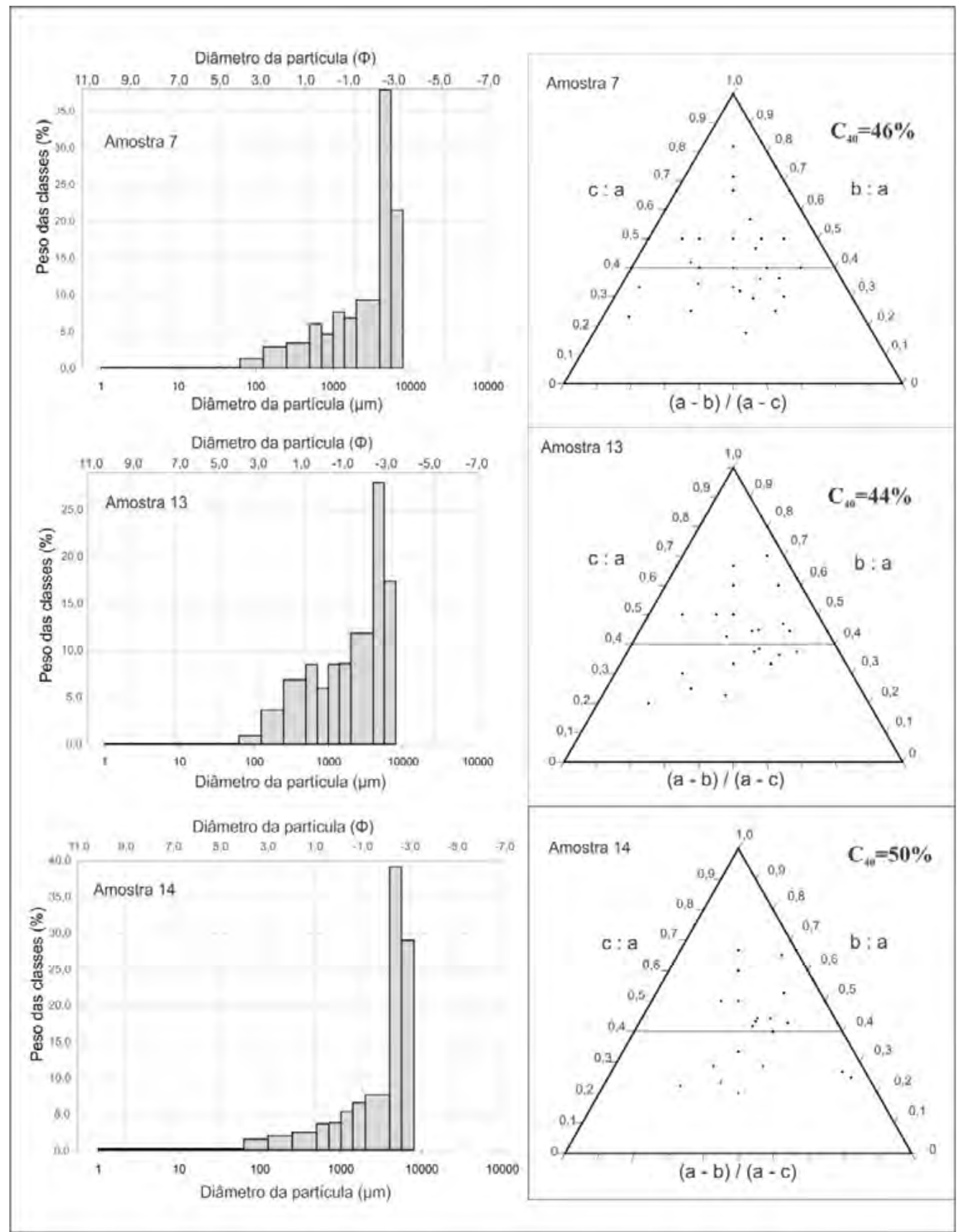

Figura 9: Análise morfoscópica e granulométrica das amostras 7, 13 e 14. A alta quantidade de cascalho indica material imaturo e pouco tempo de transporte. 


\subsection{Mapeamento geomorfológico e interpretação dos ambientes deposicionais}

A interpretação do contexto hidrológico, deposicional e relação com dinâmica da frente glacial atual possibilitou distinguir dois ambientes sedimentares na área de estudo: (a) zona de contato com gelo, ou seja, imediatamente conectado à geleira, classificada como área marginal do gelo; (b) zona de contato com a geleira por processos glaciofluviais, o ambiente proglacial marginal.

Para o mapeamento geomorfológico em detalhe a área de estudo foi dividida em 4 setores, em diferentes quadrantes, em relação a frente atual da geleira: setor 1 - geleira com pouca espessura evidenciando os flutings da base e morainas supraglaciais; setor 2 área com formação de morainas de recessão; 3 - área com gelo estagnado e morainas formadas por despejo de material sedimentar e sistema glaciofluvial bem desenvolvido; quatro - setor com morainas de avanço bem desenvolvidas (acima de $6 \mathrm{~m}$ ), formadas por empurrão durante a PIG.

- Setor 1: Há uma zona de leque glaciofluvial alimentada pela água de derretimento da geleira com declividade entre $0-8 \%$ drenando água e sedimentos para a baía Maxwell. A retração da geleira deixa o terreno exposto no período de ablação mostrando as morainas de recessão (Figura $10 \mathrm{c}$ ), formadas por material supraglacial (amostras 1 e 2) e feições deposicionais, como os flutings (Figura 10a e 10b). Os flutings demonstram-se dinâmicos quanto a sua exposição, condicionados a intensidade de ablação e derretimento da neve nesta parte de gelo estagnado, condicionados ao aporte sedimentar e hidrológico.

- Setor 2: Possui uma moraina de avanço (a moraina mais externa) proeminente na paisagem, ao lado desta têm-se o vale Norte com o canal que interliga lagos do setor 3 até o escoamento no mar, para a baía de Maxwell. O setor 2 é caracterizado por apresentar sequência de morainas de recessão (Figura 11a e 11b) de pouca extensão e altura ( $3 \mathrm{~m}$ de comprimento por $1 \mathrm{~m}$ de altura). Essas morainas estão sujeitas a retrabalhamento em fases de estabilização anual com processo de despejo (dumping) sazonal de sedimentos, porém são indicativos de retração nessa área. As morainas de recessão recentes (amostras 5 e 6) mostram-se num alinhamento perpendicular ao fluxo da geleira e com uma assimetria mais íngreme em direção à frente da geleira (Figura 11c). 


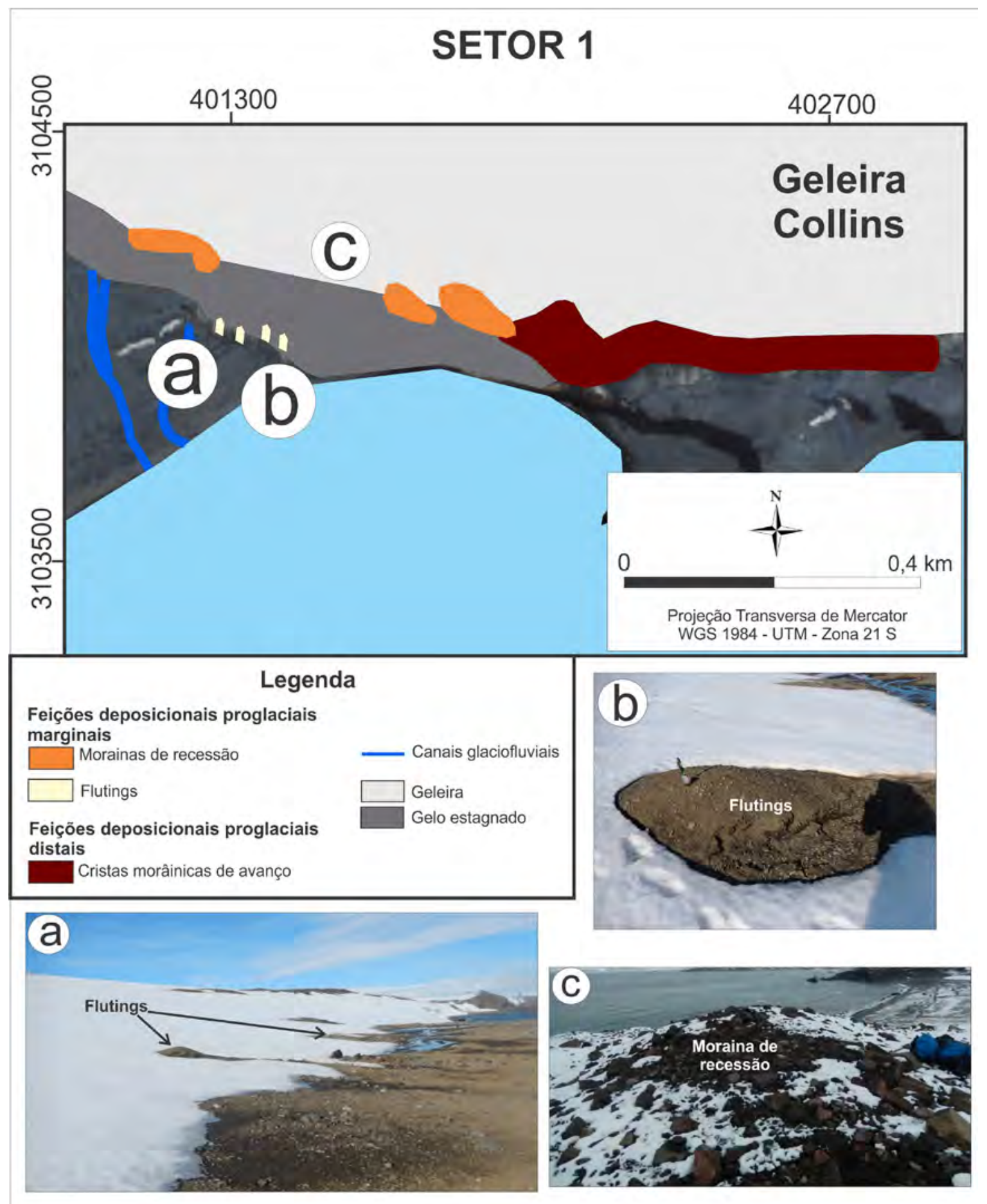

Figura 10: a) Frente da geleira Collins na porção com gelo estagnado e flutings; b) fluting; c) moraina de formação supraglacial. A retração da geleira deixa o terreno exposto no período de ablação mostrando as morainas de recessão e flutings (a, b, c). 


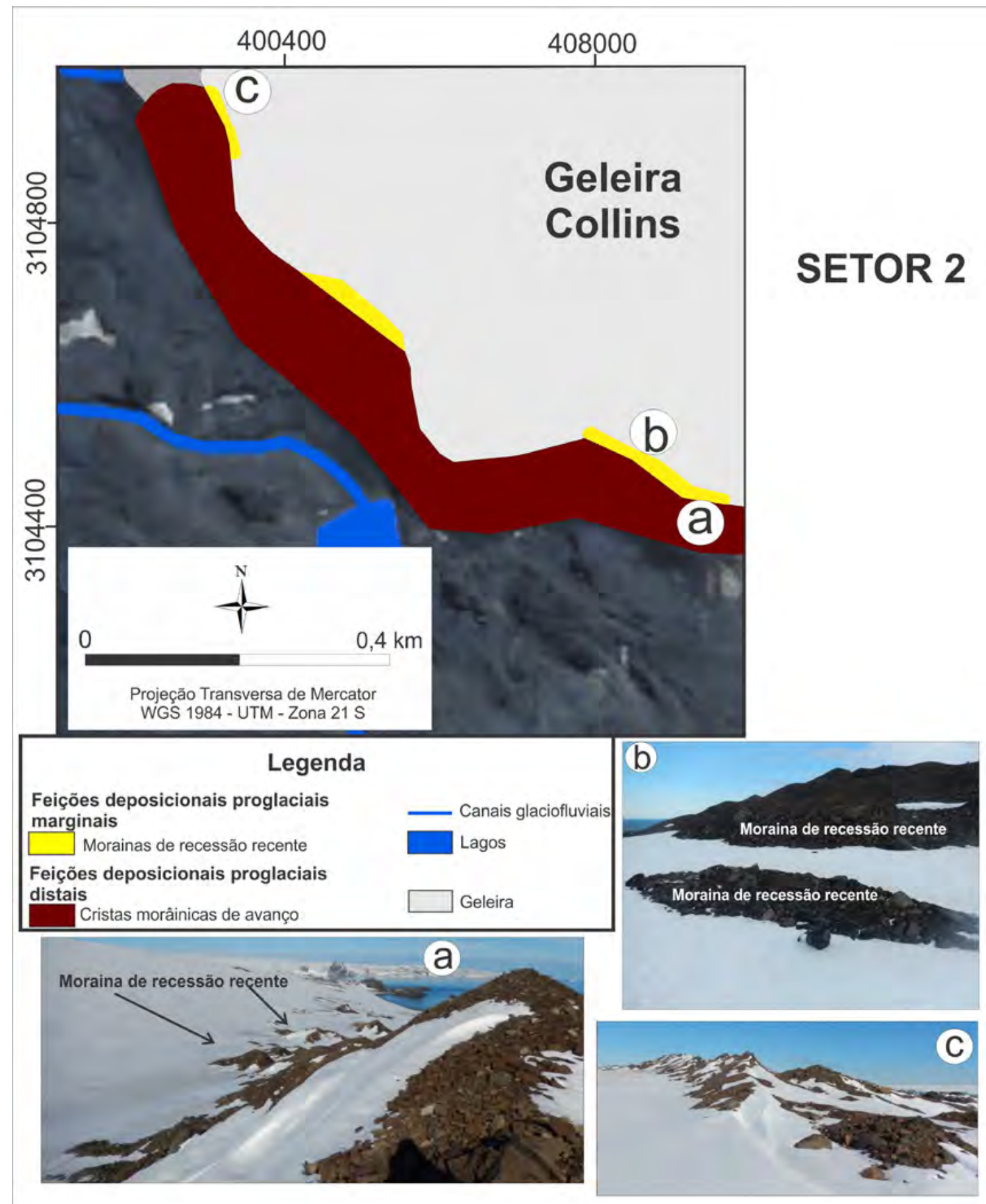

Figura 2: a) Vários montículos de morainas de recessão; b) Moraina de recessão com vista da frente da geleira; c) Perfil das morainas de recessão a esquerda, e de avanço à direita. O setor 2 é caracterizado por apresentar uma sequência de morainas de recessão (a, b, c) de pouca extensão e altura ( $3 \mathrm{~m}$ de comprimento por $1 \mathrm{~m}$ de altura). 
- Setor 3: Apresenta uma zona de leque glaciofluvial na zona proglacial (amostras 11 e 12), distante 300 $\mathrm{m}$ da frente da geleira ativa formando a cabeceira de uma rede de drenagem no sentido da baía de Maxwell com três lagos interconectados (Figura 12c). Esse obstáculo rochoso, que possui a mesma elevação que a Meseta Norte $(120 \mathrm{~m})$ provavelmente são relictos do intemperismo diferencial na área. Esse setor é o único que não tem preservação da crista morâinica de avanço citada por Hall (2007) formada na PIG. Provavelmente, devido a um obstáculo rochoso, à frente da geleira não tenha avançado tanto quanto nos demais setores (Figura $12 \mathrm{~b}$ ), tendo-se subdividido em duas direções de fluxo (NE-SO e NO-SE) e originando a moraina de recessão/estagnação na área (amostras $11 \mathrm{e}$ 12). Com a retração posterior ao último avanço da geleira (Figura 12a), e ao fluxo de água de degelo nesta área, a moraina de avanço foi retrabalhada por processos glaciofluviais.

- Setor 4: Caracteriza-se por possuir a moraina de avanço com cerca de $8-10 \mathrm{~m}$ de altura. A área possui extensão da moraina de avanço (amostra 16) em torno de $800 \mathrm{~m}$, formadas durante recessão/ estagnação (Figura 13b), muito similares (segundo a morfologia do depósito e morfoscopia sedimentar) àquelas de avanço do setor 2 (amostras 6 e 7). Observando-se na imagem de satélite, as morainas de avanço são amplamente arqueadas no plano (Figura 13a), mas no detalhe elas são irregulares e sinuosas, refletindo a morfologia da frente ativa da geleira durante a PIG.

Fazendo uma comparação entre os setores, o 3, assim como o 1, apresenta uma área com obstáculo rochoso (atualmente exposto) e fluxos de água de degelo e fusão de neve, sem preservação da moraina de avanço. Contudo, apresenta um cinturão morâinico, já retrabalhado, que indica fase de recessão/estagnação pós PIG e que atualmente delimita a frente atual da geleira com presença de gelo estagnado à jusante (Tabela 2).

A moraina de recessão do setor 4 (Figura 12c) apresenta grãos com estrias que evidenciam transporte subglacial (amostra 15). Por fim, destaca-se que o setor 2 apresenta morainas recentes pequenas (1-2 m de altura), tamanho que evidencia estabilizações da geleira em retração contínua. A pouca espessura desses depósitos aponta para a capacidade e competência de transporte, enquanto o setor 4 demonstra condições de geleira mais ativa (fluxo da geleira). 


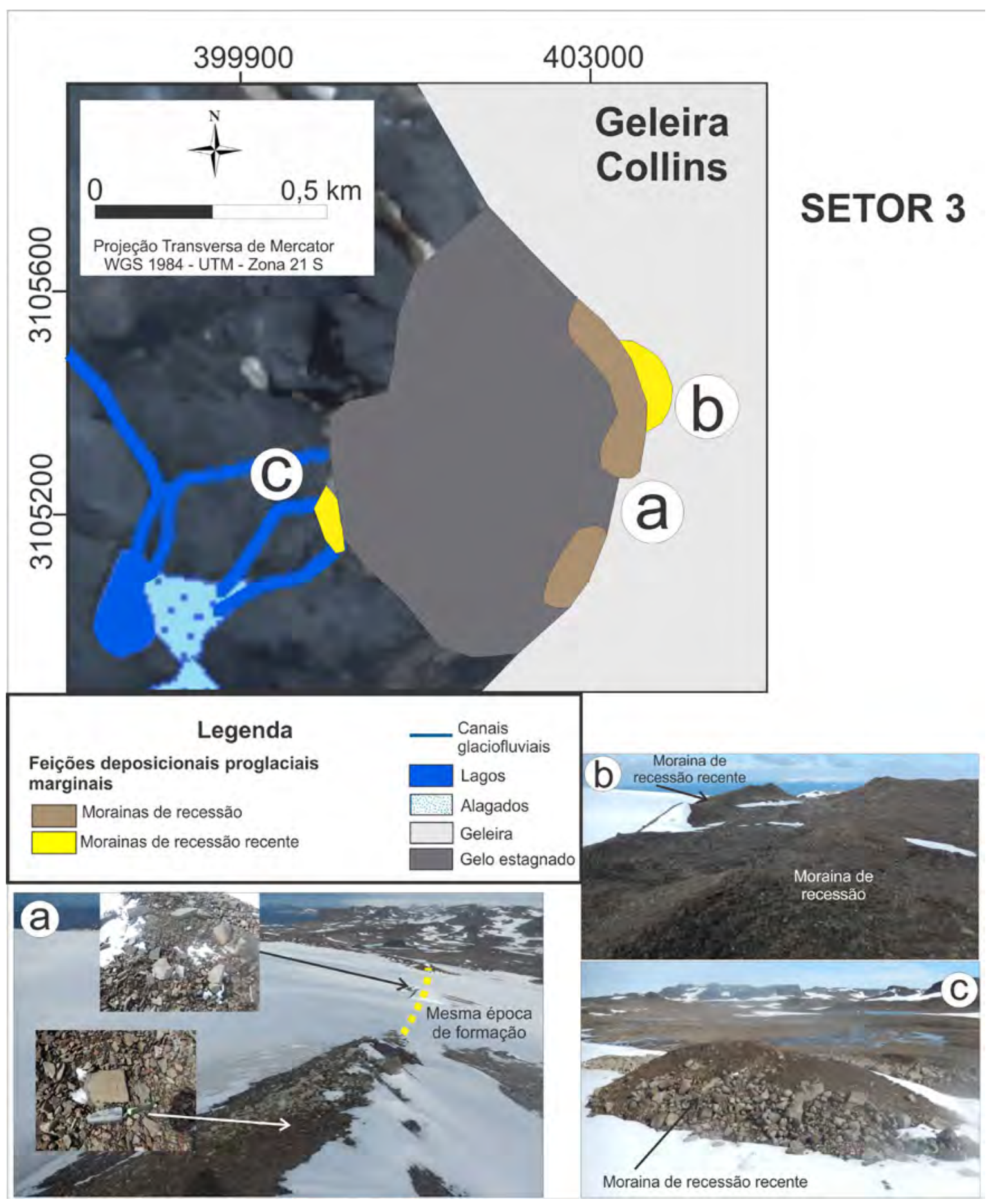

Figura 12: a) Morainas de recessão à frente de obstáculo rochoso na porção que a geleira está ativa; b) Sequência de morainas que indicam a recessão pós PIG; c) Moraina de recessão formada em ambiente glaciofluvial na zona proglacial distal. Provavelmente, devido ao obstáculo rochoso (b), a frente da geleira não avançou tanto quanto nos demais setores, tendo-se subdividido em duas direções de fluxo (NE-SO e NO-SE) e originando a moraina de recessão/estagnação na área (amostras 11 e 12). 


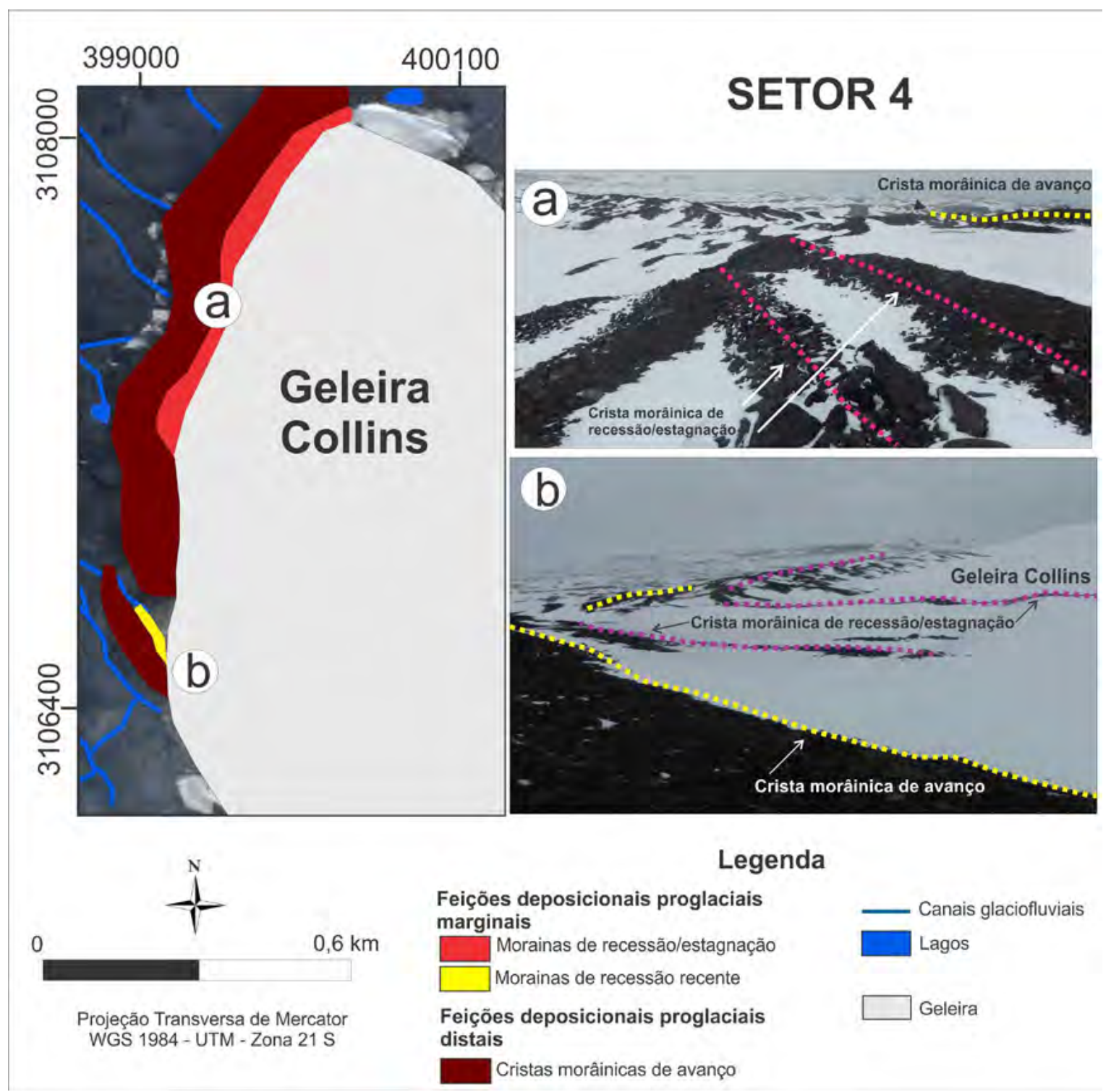

Figura 13: a) Cordões morâinicos de recessão/estagnação; b) mostra as cristas em outro ângulo de visada. Observando-se na imagem de satélite, as morainas de avanço são amplamente arqueadas no plano (a), mas no detalhe elas são irregulares e sinuosas, refletindo a morfologia da frente ativa da geleira durante a PIG.

As cristas morâinicas de avanço (setor 1, 2 e 4) apresentam material sedimentar variado, grãos angulosos representando imaturidade morfoscópica, típico de till e encontram-se intensivamente retrabalhados por processos de intemperismo físico. As cristas morâinicas supraglaciais (amostras 1 e 2) de recessão, formadas no setor 1, apresentam sedimentos imaturos textural e mosfoscopicamente, sem estrias, angulosos (média acima de $45 \%$ dos grãos examinados). Esta área apresenta pouca espessura de gelo e possui alto aporte sedimentar e hidrológico, com a formação de flutings. Essas morainas de recessão recentes e a formação de flutings indicam possível retração da geleira e diminuição da espessura apontando para uma mudança ambiental (Tabela 2). 
Tabela 2: Quadro síntese apresentando as características morfoscópicas e granulométricas, processo de formação e relevância ambiental das feições da área proglacial da geleira Collins.

\begin{tabular}{|c|c|c|c|}
\hline Feição mapeada & Características e processo de formação & Características sedimentares & Relevância ambiental \\
\hline $\begin{array}{l}\text { Cristas morâinicas } \\
\text { de avanço - setor } 1 \text {, } \\
2 \text { e } 4 \text { - amostras } 7 \text {, } \\
13 \text { e } 14 .\end{array}$ & $\begin{array}{l}\text { Possuem de } 8-10 \text { metros de altura en- } \\
\text { contram-se retrabalhadas,com grãos } \\
\text { intemperizados. Não está mais em conta- } \\
\text { to direto com a frente da geleira; formada } \\
\text { por processo de empurrão e sujeita a } \\
\text { movimentação gravitacional. }\end{array}$ & $\begin{array}{c}\mathrm{RA} \text { variando entre } 38-64 \% \mathrm{C}_{40} \text { va- } \\
\text { riando entre } 44 \% \text { e } 50 \% \text {.Predomina } \\
\text { a granulometria de cascalho, arre- } \\
\text { dondamento angular e esfericidade } \\
\text { baixa a média. }\end{array}$ & $\begin{array}{l}\text { Indica período de geleira em avanço, } \\
\text { registro da frente da geleira durante } \\
\text { avanço na PIG, alta capacidade e } \\
\text { competência de transporte de mate- } \\
\text { rial variado. }\end{array}$ \\
\hline $\begin{array}{l}\text { Morainas supragla- } \\
\text { ciais de recessão } \\
\text { - setor } 1 \text { - amostras } \\
\quad 1 \text { e } 2 \text {. }\end{array}$ & $\begin{array}{l}\text { Moraina supraglacial localizada no am- } \\
\text { biente marginal ao gelo. Material com } \\
\text { pouco transporte }\end{array}$ & $\begin{array}{l}\text { Granulometria predominante de } \\
\text { cascalho. RA entre } 45-48 \% \text { e C }_{40} \\
\text { entre } 38-45 \% .\end{array}$ & $\begin{array}{l}\text { Indica área com pouca espessura de } \\
\text { gelo e retração da geleira. }\end{array}$ \\
\hline $\begin{array}{l}\text { Flutings -Setor } 1 \\
\text {-amostras } 3 \text { e } 4 .\end{array}$ & $\begin{array}{c}\text { Depósitos de preenchimento de canais } \\
\text { subglaciais com atividade glaciofluvial; } \\
\text { localizadas em área frontal da geleira, } \\
\text { com menor espessura do gelo (voltado } \\
\text { para a baía Maxwell). }\end{array}$ & $\begin{array}{c}\text { Granulometria predomina em casca- } \\
\text { lho e areia. RA entre } 6 \text { e } 70 \% \text { e C }_{40} \text { : } \\
10 \text { e } 26 \% \text {; material que sofreu trans- } \\
\text { porte sub e englacial com transporte } \\
\text { por longa distância. }\end{array}$ & $\begin{array}{l}\text { Indica regime termal basal úmido, } \\
\text { presença de água de degelo, desliza- } \\
\text { mento basal e a orientação do fluxo } \\
\text { do gelo do setor NO-SE neste setor. }\end{array}$ \\
\hline $\begin{array}{l}\text { Cristas morâinicas } \\
\text { de recessão recen- } \\
\text { tes - setor } 2 \text { e } 3 \\
\text { - amostras } 5,6.10 \text {, } \\
\quad 11 \text { e } 12 .\end{array}$ & $\begin{array}{l}\text { Formada por processos de despejo e } \\
\text { movimentos gravitacionais pós deposi- } \\
\text { cionais; morainas com em média } 1 \mathrm{~m} \text { de } \\
\text { altura e comprimento de } 3-4 \mathrm{~m} \text {. }\end{array}$ & $\begin{array}{c}\text { Granulometria predomina em } \\
\text { cascalhos RA entre } 1 \text { e } 30 \% \text { e C }_{40} \\
\text { variando entre } 6 \% \text { e } 20 \% ; \text { material } \\
\text { geralmente arredondado e trabalhado } \\
\text { pelo transporte subglacial }\end{array}$ & $\begin{array}{l}\text { Indica retração da geleira, pouca } \\
\text { capacidade do sistema glacial trans- } \\
\text { portar material, presença de água de } \\
\text { degelo. }\end{array}$ \\
\hline $\begin{array}{l}\text { Cristas morâinicas } \\
\text { de recessão - setor } \\
3 \text { - amostras } 8 \text { e } 9\end{array}$ & $\begin{array}{l}\text { Formadas por processos de empurrão e } \\
\text { despejo de sedimentos; altura média de } \\
5 \mathrm{~m} \text {; cristas morâinicas que provavel- } \\
\text { mente no passado tiveram continuidade } \\
\text { longitudinal num processo de retração/ } \\
\text { estagnação da geleira. }\end{array}$ & $\begin{array}{l}\text { Predomina granulometria de cas- } \\
\text { calho; RA entre } 50 \text { e } 67 \% \text { e } \mathrm{C}_{40} \\
\text { entre } 20 \text { e } 27 \% \text {; material próximo a } \\
\text { obstáculo rochoso e pouco tempo de } \\
\text { transporte }\end{array}$ & $\begin{array}{c}\text { Indica uma área de gelo estagnado; } \\
\text { morainas localizadas no ambiente } \\
\text { de gelo estagnado, portanto em } \\
\text { transição de contato com o gelo para } \\
\text { proglacial. }\end{array}$ \\
\hline $\begin{array}{l}\text { Cristas morâini- } \\
\text { cas de recessão/ } \\
\text { estagnação - setor } \\
4 \text { (amostras } 15,16 \\
\quad \text { e 17) }\end{array}$ & $\begin{array}{l}\text { Formada por processos de empurrão com } \\
\text { compressão e despejo de sedimentos; } \\
\text { crista morâinica de aproximadamente } 6 \\
\text { a } 8 \text { m de altura; formada pela recessão/ } \\
\text { estagnação da geleira. }\end{array}$ & $\begin{array}{c}\text { Predomina granulometria de areia; } \\
\text { RA variando entre } 35 \% \text { e } 63 \% \text { e } \mathrm{C}_{40} \\
\text { variando entre } 16 \text { e } 25 \% \text {; morainas } \\
\text { formadas numa área ativa da geleira, } \\
\text { material pobremente selecionado, } \\
\text { com material de variadas origens de } \\
\text { transporte na geleira e pouco tempo } \\
\text { de transporte. }\end{array}$ & $\begin{array}{l}\text { Evidencia uma área ativa da geleira, } \\
\text { com capacidade de transporte de ma- } \\
\text { terial de granulometria variada nas } \\
\text { feições, indicando a área de maior } \\
\text { fluxo da geleira. }\end{array}$ \\
\hline
\end{tabular}

\section{Considerações finais}

As principais feições deposicionais encontradas foram cristas morâinica de avanço, em geral 8-10 m acima da área a sua frente, geoforma resultante da expansão da geleira na PIG formada por processos de empurrão; morainas de recessão apresentadas em montículos e associadas a processos de empurrão sazonal; morainas de recessão que formam montículos ou pequenas cristas formadas por processos de despejo, empurrão e compressão; flutings formados de sedimentos subglaciais e morainas supraglaciais formadas em áreas de pouca espessura da geleira.

O mapeamento foi importante para identificar as áreas de retração e também na interpretação de zonas com gelo estagnado que, provavelmente, serão as futuras áreas expostas submetidas a processos relacionados a ambientes marginais ao gelo. Os setores 1, 2 e 3 apresentam uma série de feições morâinicas de recessão e flutings que indicam geleira em retração, diminuição da espessura do gelo e interferência do relevo subglacial implicando na diminuição da velocidade de deslizamento basal da geleira e competência de transporte, resultando em material arredondado e pouco anguloso. Já o setor 4, pela continuidade das cristas morâinicas de avanço e recessão/estagnação, indica sistema glacial ativo com capacidade de transporte de material de diferentes tamanhos e quantidade.

Foram identificadas três áreas de gelo estagnado (setores 1, 3 e 4) com transição do ambiente de contato com o gelo para ambiente proglacial. Essas áreas de gelo estagnados em anos de muita ablação não estão mais conectadas ao sistema glacial, como pode ser observado na imagem QuickBird (Figura 1) utilizada para o mapeamento geomorfológico. Ambientalmente, essas áreas indicam os setores mais frágeis e que provavelmente serão as primeiras a sofrerem retração nos próximos anos.

O mapeamento elaborado a partir das amostras sedimentares permitiu interpretar, a partir dos ambientes de sedimentação, diferentes comportamentos da geleira, com avanço durante a PIG e das posteriores fases de recessão/estagnação. 


\section{Referências}

Bennett, M. R.; Glasser, N. F. 1996. Glacial Geology - Ice Sheets and Landforms. Inglaterra, John Wiley, 364 p.

Benn, D. I.; Evans, D. J. A. 2010. Glaciers and Glaciation. Londres: Arnold, 734 p.

Bigarella, J. J.; Hartkopf, C. C.; Sobanski, A. \& Trevisan, N. 1955. Textura superficial dos grãos em areias e arenitos. Arquivos de Biologia e Tecnologia, X: 253-275.

Birkenmajer, K., Soliani, E., Kawashita, K. 1990. Reliability of Potassium argon dating of Cretaceous Tertiary island-arc volcanic suites of King George Island, South Shetland Islands (West Antarctica). Bulletin Acaddemic Polonish. Science, v. 30, p. 133-143.

Bremer, U. F. 2008. Solos e geomorfologia da borda leste da península Warszawa, Ilha Rei George, Antártica Marítima. 136 f. Tese (Doutorado em Solos e Nutrição de Plantas) Universidade Federal de Viçosa.

Eklund, A.; Hart, J. K. 1996. Glaciotectonic deformation within a flute from the glacier Isfallsglaciären, Sweden. Journal Quaternary Science, v. 11, p. 299-310.

Fountain, A. G.; Walder, J. S. 1998. Water flow through temperate glaciers. Review Geophysical, n. 36, p. 299-328

Glasser, N. F.; Hambrey, M. J. 2002. Sedimentary facies and landform genesis at a temperate outlet glacier: Soler Glacier, North Patagonian Icefield. Sedimentology, v. 49 (1), p. 43-64.

Glasser, N. F.; Jansson, K. N.; Harrison, S.; Rivera, A. 2005. Geomorphological evidence for variations of the North Patagonian Icefield during the Holocene. Geomorphology. n. 71, p. 263-277.

Gustavsson, M., Kolstrup, E., Seijmonsbergen, A. C. 2006. A new symbol-and-GIS based detailed geomorphological mapping system: renewal of a scientific discipline for understanding landscape development. Geomorphology, v. 77, p. 90-111.

Hall, B. 2007. Late-Holocene advance of the Collins Ice Cap, King George Island, South Shetland Islands. The Holocene, v. 17, p. $1253-1258$.
Hawkes, D. D. 1961. The geology of South Shetland Islands. The petrology of King George Island. Scientific Reports of the Falkland Islands Dependencies Survey, v. 26, p. 1-28.

Hubbard, B.; Glasser, N. 2005. Field Techniques in glaciology and glacial geomorphology. West Sussex: John Wiley, 400 p.

Krumbein, W. C. 1941. Measurement and geological significance of shape and roundness of sedimentary particles. Journal of Sedimentary Petrology, v. 11, p. 64-72.

Mercier, D. 2008. (ed.) Paraglaciaire et changements climatiques, Bulletin de 1'Association de Géographes Français, v. 2, p. 131-208.

Mercier, D., Étienne, S. 2008. (Ed.) Paraglacial geomorphology: processes and paraglacial context, Geomorphology, v. 95, p. $1-10$.

Michel, R. F. M.; Schaefer, C. E. G. R.; López-Martínez, J.; Simas, F. N. B.; Haus, N. W.; Serrano, E.; Bockheim, J. G. 2014. Soils and landforms from Fildes Peninsula and Ardley Island, Maritime Antarctica, Geomorphology, v. 225, p. 76-86.

Rittenhouse, G. 1943. A visual method for estimating twodimensional sphericity. Journal of Sedimentary Petrology, v. 13, p. 79-81.

Simas, F., C.; Schaefer, M. F. F; Dacosta, I. 2008. Genesis, properties and classification of cryosols from admiralty Bay, Maritime Antarctica. Geoderma, 144 (1-2), p. 116-122.

Simões, C. L.; Rosa, K. K.; Czapela, F.; Vieira, R.; Simoes, J. C. 2015. Collins Glacier Retreat Process and Regional Climatic Variations, King George Island, Antarctica. Geographical Review, v. 105, p. 462-471.

Smith, M. J.; Clark, C. D. 2005. Methods for the visualisation of digital elevation models for landform mapping. Earth Surface Processes and Landforms, n. 30 (7), p. 885-900.

Smellie, J. L. 1983. Syn-plutonic origin and Tertiary age for the PreCambrian False Bay schists of Livingston Island, South Shetland Islands. British Antarctic Survey Bulletin, v. 52, p. 21-32.

Wentworth, C. K. 1922. A scale of grade and class terms for clastic sediments. Journal of Geology, v. 3, p. 377-392. 